\title{
STUDIES ON OPTICAL PROPERTIES OF PVA BASED COMPLEX POLYMER ELECTROLYTE
}

\author{
M. Gnana Kiran ${ }^{1,2,}$, N. Krishna Jyothi ${ }^{1}$, K. Samatha ${ }^{2}$, M. P. Rao ${ }^{2}$ \\ and V. B. V. N. Prasad ${ }^{3}$ \\ ${ }^{1}$ Department of Physics, Koneru Lakshmaiah Education Foundation, \\ Vaddeswaram, A.P, India. \\ ${ }^{2}$ Department of Physics, Andhra University, Vizag, Andhra.Pradesh, India. \\ ${ }^{3}$ Department of Mathematics, Koneru Lakshmaiah Education Foundation, . \\ Vaddeswaram, A.P, India \\ Corresponding Author: gnanakiran33@gmail.com
}

\begin{abstract}
Solid Polymer Electrolytes (SPE) based on polymer (PVA) Polyvinyl Alcohol is doped with Sodium $\mathrm{Nitrate}\left(\mathrm{NaNO}_{3}\right)$, a membrane is prepared by solution casting method. Here outcomes of the optical transmission, optical absorption, optical absorption coefficient, optical refractive index, optical extinction coefficient, direct energy band gaps, indirect energy bandgap, absorption edge, estimated band gap, optical conductance studies are given. Optical properties are taken by UV-visible (Ultraviolet-visible) Absorption spectroscopy wavelength within the range of $200 \mathrm{~nm}$ to $800 \mathrm{~nm}$. optical transmittance wavelength is $200 \mathrm{~nm}$. Energy band gap changes from $5.6 \mathrm{eV}$ to $4.9 \mathrm{eV}$. Indirect, direct and absorption edge is high for polymer pure PVA. By increasing the salt concentration to the polymer the abovementioned parameters are decreasing gradually. For the concentration of $70 \%$ PVA: $30 \% \mathrm{NaNO}_{3}$ has a low value of direct and indirect energy bandgap.
\end{abstract}

Keywords: Solid Polymer electrolyte film, absorption, transmittance, refractive index, absorption coefficient, energy band gap, optical conductance.

RASĀYAN J. Chem., Vol. 14, No.2, 2021

\section{INTRODUCTION}

Material research aims to prepare new material properties with an application to identify the chemical, physical processes that establish the properties. In this process, the material is combining with the polymers in different concentrations. ${ }^{1}$ The given Polymer electrolytes (PE) properties are generally analyzed for fundamental purposes and useful applications. Polymer-based electrolytes are not only combining the useful properties of polymers and dopant, but it also shows various new-found properties. ${ }^{2}$ The polymer properties can be enhanced and regulated substantially by combining a proper dopant. ${ }^{3}$

Polyvinyl Alcohol, which is prepared from polyvinyl acetate. It is very simply degradable in biological organisms and completely soluble in inorganic liquids such as water and ammonia, etc ${ }^{4}$. PVA is a semisynthetic polymer that is used worldwide during the 20th century. When PVA is doped with an inorganic salt, the dopant interacts with the O-H group of PVA either in the crystalline phase or the amorphous phase after that changes its properties. ${ }^{1}$

It is used in the medical, industrial, commercial, and food packing sectors. It is utilized to generate a lot of products, like resins, surgical threads, and food-related packing materials. ${ }^{5,6}$ PVA is one of the biodegradable type materials and is used in textile sizing and paper coating. ${ }^{7}$ This type of polymer is usually used by mixing other polymers then it is used for several drug and chemical industries. ${ }^{8,9}$

\section{EXPERIMENTAL}

PVA (polyvinyl alcohol) is bought from Sigma Aldrich chemicals. Based on biopolymer electrolytes films are doped with pure sodium nitrate $\left(\mathrm{NaNO}_{3}\right)$ are prepared in various ratios $(90: 10)(80: 20),(70: 30)$ and (60:40) by solution casting method. Various concentrations of PVA and $\mathrm{NaNO}_{3}$ are combined with double distilled water as a solvent. The blend of the solution is stirred for 12 hours by keeping the temperature

Rasayan J. Chem., 14(2), 760-767(2021)

http://dx.doi.org/10.31788/ RJC.2021.1425964

This work is licensed under a CC BY 4.0 license. 
RASĀYAN J. Chem.

Vol. 14 | No. 2 |760-767| April - June | 2021

$60^{\circ} \mathrm{C}$. Then the homogeneous solution is formed, and it is poured into polypropylene dishes and kept in a vacuum chamber at $60^{\circ} \mathrm{C}$. Water in this homogeneous solution is evaporated slowly under the vacuum drying process. After 24 hours the partial transparent films are formed. These films are taken from polypropylene dishes and positioned in a vacuum desiccator up to the next test. The dried polymer films are characterized by the JASCO (V-670) UV-VIS-NIR Photo Spectrometer. The effect of solvent in the solid polymer electrolyte, optical parameters, and optical characterizations are studied from the UV-Visible spectrometer at normal temperature.

\section{Absorption and Absorption Coefficient Studies}

\section{RESULTS AND DISCUSSION}

UV absorption spectra are obtained under room temperature. UV Spectrometer is used to determine the absorption spectra of the sample wavelength range of $200 \mathrm{~nm}-900 \mathrm{~nm}$. The absorption optical studies are applied to examine the optic transition and structure of the film sample. Here in this spectrum, the absorption shows between $260 \mathrm{~nm}-340 \mathrm{~nm}$. The pure and different doped concentrations of $\mathrm{NaNO}_{3}$ are represented in given Fig.-1. In polymers, several electron transitions may occur. ${ }^{10}$ The absorption spectra show a strong growth absorption at a wavelength near to absorption edge.

Band structure, absorption edge and optical energy band gaps are determined by absorption studies. No absorption is seen for pure polymer but by increasing doping concentration the absorption is increasing gradually. ${ }^{11}$ The absorption increases up to PVA 70\%: $\mathrm{NaNO}_{3} 30 \%$ arrived at $280 \mathrm{~nm}$. In this research at this concentration, the change in the band structure and coefficient of absorption is high. Again this absorption is decreased for PVA $60 \%: \mathrm{NaNO}_{3} 40 \%$ concentration. The optical absorption can be measured by a coefficient of absorption $\left(\alpha\right.$.), which is also named as a power fraction of material absorption. ${ }^{12}$

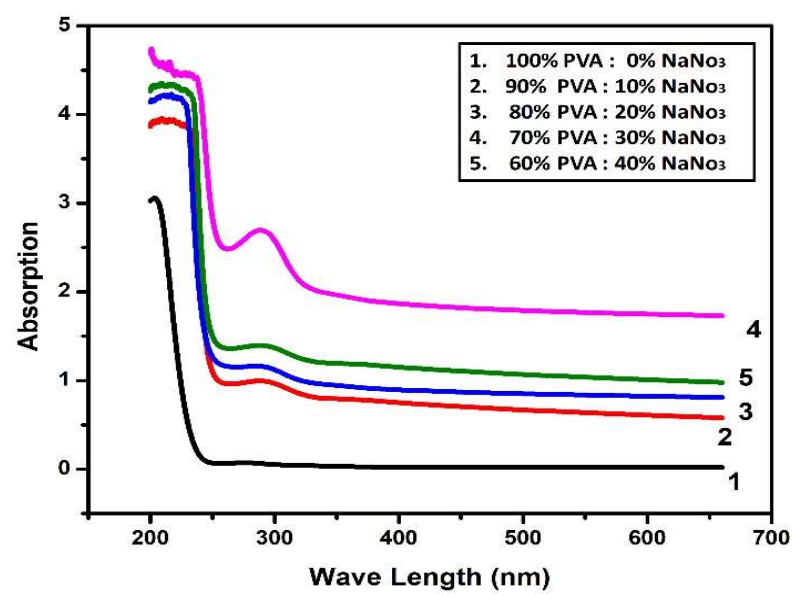

Fig.-1: PVA and $\mathrm{NaNO}_{3}$ Various wt.\% Ratios of Optical Absorption Spectra

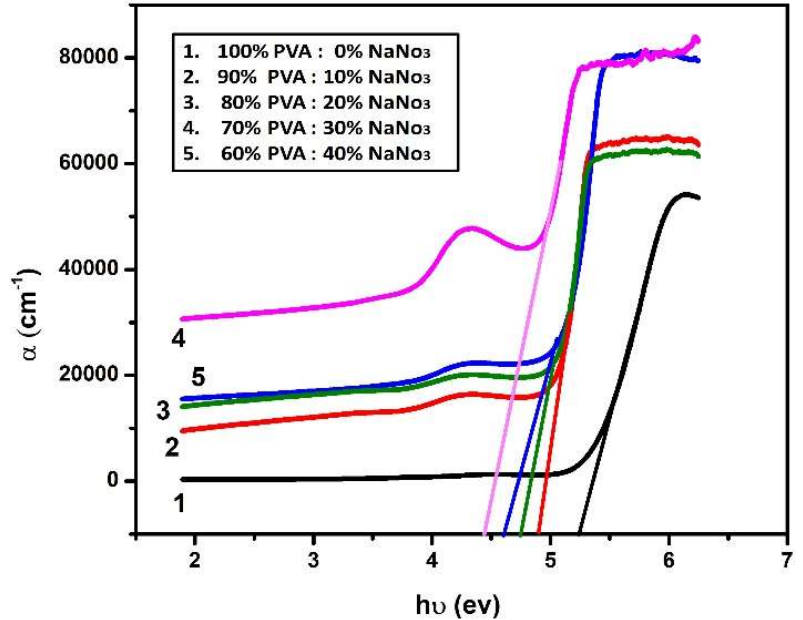

Fig.-2: PVA and $\mathrm{NaNO}_{3}$ Various wt.\% Ratios of Optical Absorption Coefficient Spectra 
RASĀYAN J. Chem.

Vol. 14 | No. 2 |760-767| April - June | 2021

The coefficient of optical absorption can be analyzed by using the given formula.

$$
\alpha=\frac{2.303}{t} \times A
$$

Where ' $A$ ' is data from optical absorption, ' $d$ ' is the thickness of a given sample. Here Fig.-2 signifies the coefficient absorption vs. the energy of photon for pure and doped concentrations. It is cleared that lower photon energy is absorbed for PVA $70 \%: \mathrm{NaNO}_{3} 30 \%$ concentration and the photon energy is shifted towards lower energy. Photon energy range from $5.25 \mathrm{eV}-4.45 \mathrm{eV}$ represents a reduction of band energy gaps of doped samples.

\section{Transmittance}

Transmission spectra for PVA pure composites with several ratios of $\mathrm{NaNO}_{3}$ are calculated in the wavelength range $(200 \mathrm{~nm}-800 \mathrm{~nm})$ is indicated in Fig.-3, It is detected that pure PVA is a high transmission and decreases by rising the dopant concentration of $\mathrm{NaNO}_{3}{ }^{13}$. The transmission decreases in PVA samples by increasing $\mathrm{NaNO}_{3}$ concentration leads to reduction. ${ }^{14}$ A small transmission is noticed at about $293 \mathrm{~nm}$. If optical absorption is more and the optical transmission is at a low level. Due to this, its occurred low optical transmission for PVA 70\%: $30 \% \mathrm{NaNO}_{3}$ concentration. The photon energy is perfectly observed by the films then it transmits a very low amount of energy.

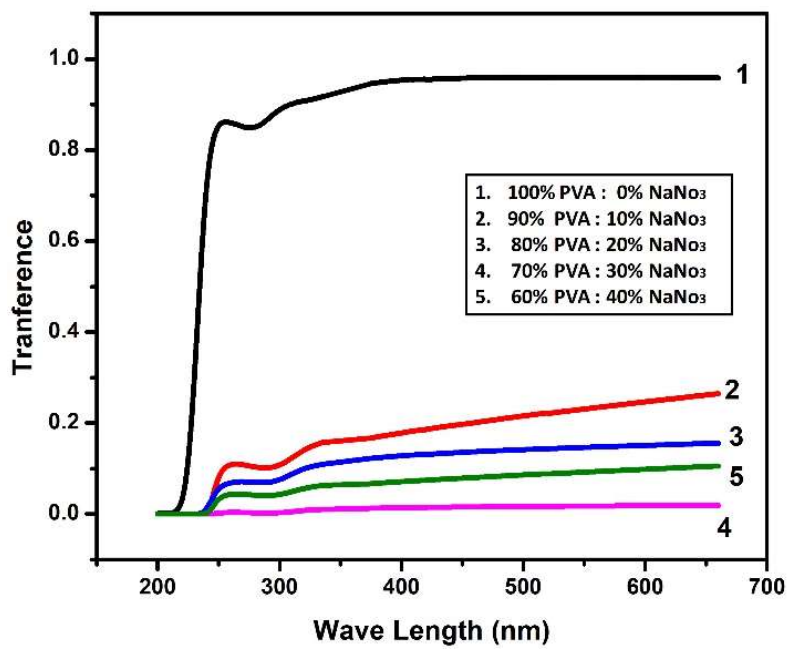

Fig.-3: PVA and $\mathrm{NaNO}_{3}$ Various wt.\% Ratios of Optical Transmittance Spectra

The transmittance ' $T$ ' is the ratio of two terms such as power radiant transmission $(P)$ by sample material and power of radiant incidence $\left(P_{0}\right)$.

But, $P=P_{0} \mathrm{~T}$

$$
T=e^{\alpha t}
$$

Where ' $\alpha$ ' is an optical coefficient of absorption and ' $t$ ' is the thickness of the sample material, optical transmission can be calculated from optical absorbance data. The transmission spectrum samples from 200 $\mathrm{nm}-293 \mathrm{~nm}$ are displayed in the plot. The optical reflectance can produce a refractive index and many optical parameters. The reflectance of the film is calculated from a given relation.

$$
\mathrm{R}=1-(\mathrm{T}+\mathrm{A})
$$

Where ' $\mathrm{T}$ ' is an optical transmittance and ' $\mathrm{A}$ ' is optical absorption.

\section{Refractive Index}

Optical properties of optical extinction coefficient and optical refractive index can produce an optical constant of the material. ${ }^{15}$ Specific optoelectronics applications relate to this refractive index, atomic structure, electrical properties, and electronic bond structure. The given figure 4 indicates the material refractive index for pure polymer PVA and various salt concentrations of $\mathrm{NaNO}_{3}$. The optical refractive 
RASĀYAN J. Chem.

Vol. 14 | No. 2 |760-767| April - June | 2021

index is calculated from optical reflectance ' $R$ '. ${ }^{16}$ This is the very basic property of the material and it can show dispersion at all wavelengths of light.

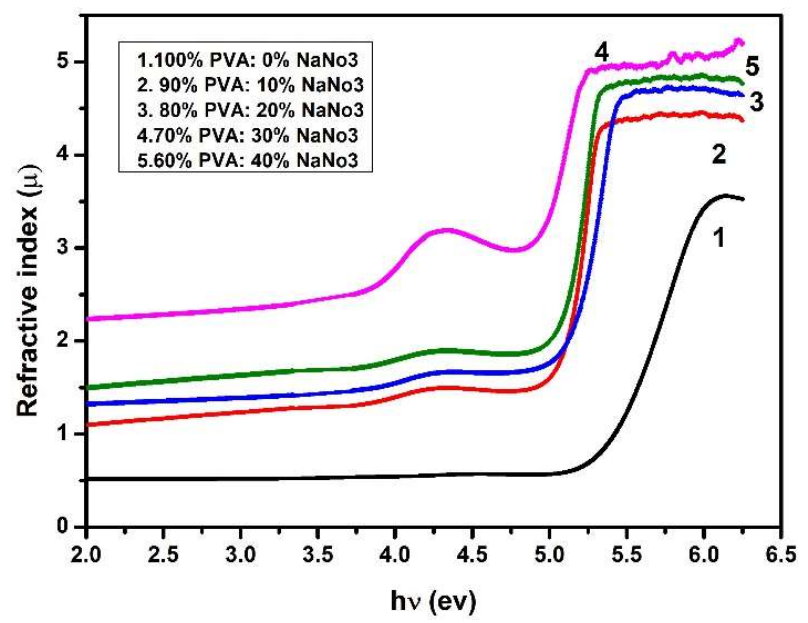

Fig.-4: PVA and $\mathrm{NaNO}_{3}$ Various wt.\% Ratios of Optical Refractive Index Spectra

The refractive index of an optical material indicates electronic and molecular polarization of the electromagnetic field of light. These plots showing the change in the refractive index. The refractive index nearly minor and constant for all samples up to $4 \mathrm{eV}$, it can increase by increasing photon energy. Then after again they become constant. Normally by increasing doping concentration, the refractive index is also changed by changing the dopant concentration to the polymer. Finally, the optical refractive index is high for $70 \%$ PVA: $30 \% \mathrm{NaNO}_{3}$. Then subsequently, electronic and molecular polarization and dispersion are very high and wavelength is the lower value.

The reflectance in terms of optical refractive index is given by

And

$$
R=\frac{(n-1)^{2}+K^{2}}{(n+1)^{2}+K^{2}}
$$

$$
n=\frac{1+\sqrt{R}}{1-\sqrt{R}}
$$

Here optical reflectance is ' $R$ ', ' $K$ ' is a coefficient of extinction, ' $n$ ' is the refractive index of the sample.

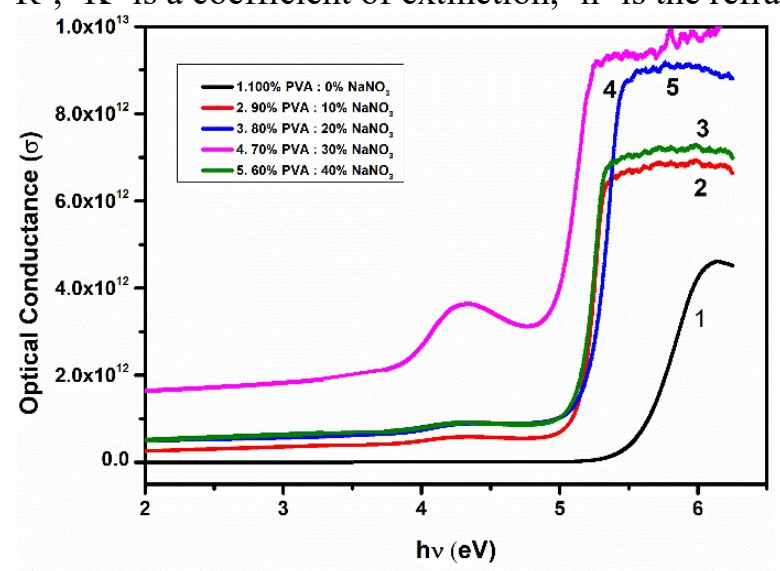

Fig.-5: PVA and $\mathrm{NaNO}_{3}$ Various wt.\% Ratios of Optical Conductance Spectra

Figure-5 can show the plots between optical conductance and photon energy. In this result, the conductance is increased by increasing doped concentration. Finally, $70 \%$ PVA: $30 \% \mathrm{NaNO}_{3}$ showed the maximum 
RASĀYAN J. Chem.

Vol. 14 | No. 2 |760-767| April - June | 2021

value. ${ }^{17}$ The optical absorption and transmission take place due to the orientation and polarization of the particles. The refractive index is changed by changing the orientation of the particles. Finally, these parameters affect the material conductivity. $70 \%$ PVA: $30 \% \mathrm{NaNO}_{3}$ concentration achieved the maximum conductivity due to optical absorption and refractive index. The optical conductance value is obtained from coefficient absorption, optical refractive index, and speed (velocity) of the light passing through the pure and doped concentration sample material. the expression for optical conductance is represented by.

$$
\sigma=\frac{\alpha n c}{4 \pi}
$$

Here ' $\alpha$ ' is the coefficient of absorption, ' $n$ ' is the refractive index value for the sample, ' $c$ ' is the speed of light.

\section{Extinction Coefficient (K)}

The extinction coefficient is represented as an imaginary component of the optical refractive index. In the given figure 6 extinction coefficient spectra versus wavelength behaviour are shown for different doped concentrations polymer PVA and salt $\mathrm{NaNO}_{3}{ }^{18}$. The variation of the excitation coefficient with wavelength shows such interaction between medium and photon energy. The small fraction of electromagnetic energy(Light energy) loss is known as coefficient extinction. Optical absorption is an effect on the extinction coefficient. Due to this reason only the extinction coefficient value is maximum for $70 \%$ PVA: $30 \% \mathrm{NaNO}_{3}$ concentration. In the given graph extinction coefficient is increased by raising the wavelength and doping concentration. Then its value is improved up to $70 \% \mathrm{PVA}: 30 \% \mathrm{NaNO}_{3}$. Again by increasing salt doping concentration, it starts to decrease. ${ }^{19}$

We can calculate the optical excitation coefficient from the formula:

$$
K=\frac{\alpha \lambda}{4 \pi}
$$

Here ' $\lambda$ ' represents wavelength, ' $\alpha$ ' is coefficient absorption. With the help of this excitation, the coefficient can calculate real, imaginary, and complex parts.

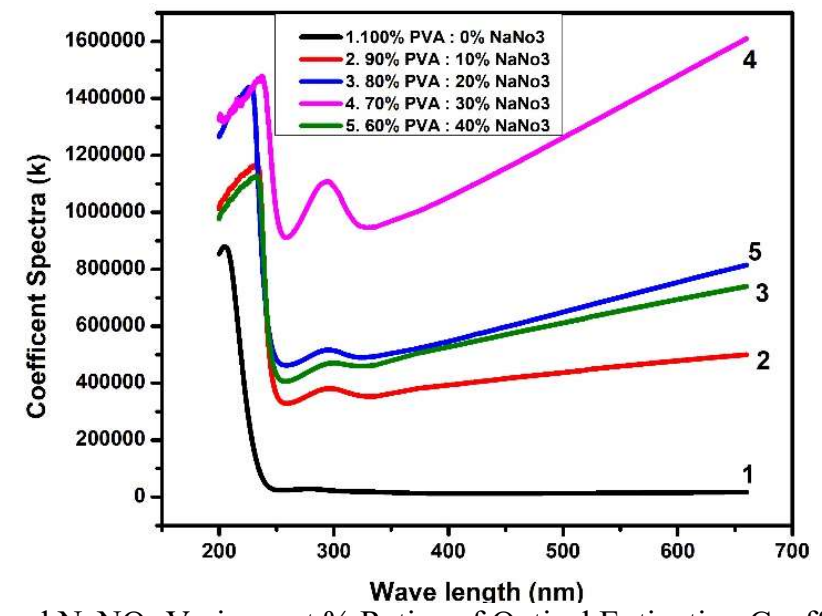

\section{Energy Band Gap}

Fig.-6: PVA and $\mathrm{NaNO}_{3}$ Various wt.\% Ratios of Optical Extinction Coefficient Spectra

Data from the graph can be achieved from the study of optical absorption. Mostly, the bandgap is dividing semiconductors and insulators into two major parts, they are direct energy bandgap and indirect energy bandgap materials. Valence and conduction bands both are exhibited a very less (zero) crystal momentum indirect bandgap. ${ }^{20}$ But In the indirect bandgap, the conduction band doesn't agree to crystal zero momentum and shift of the phonon energy. ${ }^{21}$ Shalliday and Davis had explained both the direct and indirect bandgap that occur near the basic edge of the band can be described from the plots $(\alpha h v)^{2} \&(\alpha h v)^{1 / 2} \mathrm{Vs}$. photon energy (hv). Optical absorption edge, absorption, transmission, and electron shift from valency to the conduction band is determined by wavelength or photon energy (hv). ${ }^{22}$ 
RASĀYAN J. Chem.

Vol. 14 | No. 2 |760-767| April - June | 2021

The energy bandgap is determined from the graph of $(\alpha h v)^{\mathrm{x}} \mathrm{vs.}(\mathrm{h} v)$ photon energy. ${ }^{23}$ The acquired values of energy band gaps are represented in Table-1. The energy bandgap values attained from Fig.- 7 and Fig.8 , are the plot representing forbidden indirect transition $(x=1 / 2)$ and allowed indirect transition $(x=2 / 3)$ respectively. The results of the energy bandgap for direct electronic transition $(x=2)$ are representing in Fig.-9. Here $(\alpha h v)^{2}$ vs. photon energy ' $h v$ ' generates the direct bandgap value. In this present research work, a bandgap of $5.6 \mathrm{eV}$ is obtained for pure PVA. In this UV-visible spectrum. The absorbance is decreased by increasing the wavelength.

A decrease in absorption shows the identification of an optical bandgap of the material. ${ }^{24}$ The absorption edge, direct bandgap, indirect allowed and forbidden gap are decreased by increasing the doping concentrations are given in Table-1. For all the above-mentioned parameters band gaps are minimum for the concentration $70 \%$ PVA: $30 \% \mathrm{NaNO}_{3}$ and from here again band gaps are increased by increasing the doping concentrations. Here in the given data, $E_{g}$ decreases by increasing the dopant salt percentage. ${ }^{22}$

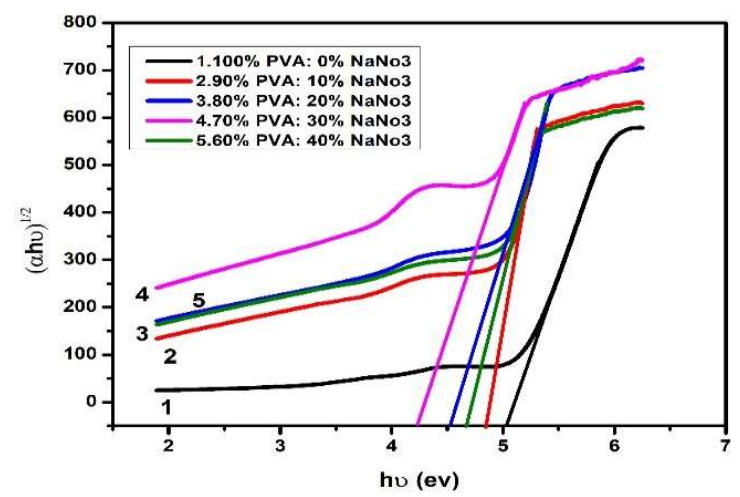

Fig.-7: PVA and $\mathrm{NaNO}_{3}$ Various wt.\% Ratios of Forbidden Indirect Energy Bandgap Spectra

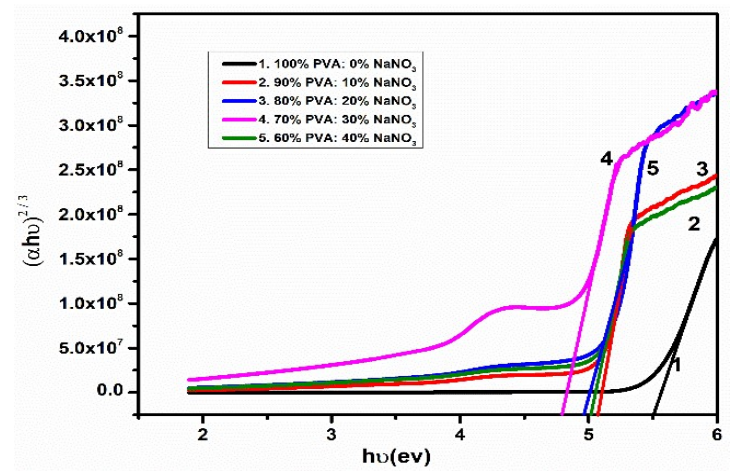

Fig.-8: PVA and $\mathrm{NaNO}_{3}$ Various wt.\% Ratios of allowed Indirect Energy Bandgap Spectra

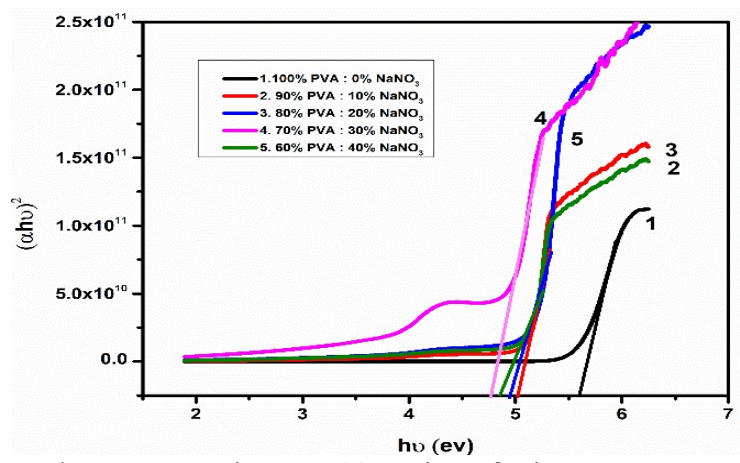

Fig.-9: PVA and $\mathrm{NaNO}_{3}$ Various wt.\% Ratios of Direct Energy Bandgap Spectra 
RASĀYAN J. Chem.

Vol. 14 | No. 2 |760-767| April - June | 2021

.Table-1: Optical Parameters for Pure .PVA and .PVA: . $\mathrm{NaNO}_{3}$ Doped Concentrations

\begin{tabular}{|c|c|c|c|c|c|}
\hline Composition & 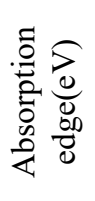 & 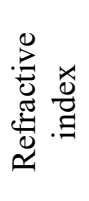 & 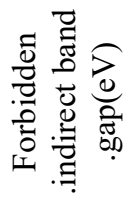 & 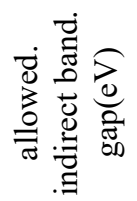 & 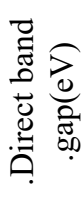 \\
\hline $100 \%$ PVA: $0 \% \mathrm{NaNO}_{3}$ & 5.25 & 0.52 & 5.03 & 5.51 & 5.6 \\
\hline $90 \%$ PVA: $10 \% \mathrm{NaNO}_{3}$ & 4.93 & 1.06 & 4.84 & 5.07 & 5.11 \\
\hline $80 \%$ PVA: $20 \% \mathrm{NaNO}_{3}$ & 4.74 & 1.33 & 4.67 & 5.02 & 5.05 \\
\hline $70 \%$ PVA: $30 \% \mathrm{NaNO}_{3}$ & 4.4 & 2.23 & 4.24 & 4.79 & 4.93 \\
\hline $60 \%$ PVA: $40 \% \mathrm{NaNO}_{3}$ & 4.6 & 1.5 & 4.52 & 4.96 & 4.98 \\
\hline
\end{tabular}

\section{CONCLUSION}

In this present research, Solid Polymer Electrolyte membranes (SPE) are made by different concentrations (PVA: $\mathrm{NaNO}_{3}$ ) (pure PVA, 90:10, 80:20, 70:30, 60:40 wt\%) using solution casting technique. The study and evaluation of optical parameters for doped $\mathrm{NaNO}_{3}$ with PVA are observed and the optical studies of the film are explained and identified that the material optical refractive index is increased by increasing of doping content of $\mathrm{NaNO}_{3}$ into the PVA. An optical refractive index is changing by optical conductance of material and parallelly the density of the electrolyte is enhanced by an increase in the concentration of $\mathrm{NaNO}_{3}$. By comparing the films, it is clarified that electrical energy disappears in highly doped composition than less doped composition materials. The optical conductivity is reduced gradually by decreasing photon energy ' $h v$ ' and finally it becomes constant value gradually. The result suggested that the drop in optical sample conductivity is caused by reducing the energy of photon ' $h v$ '. The reduction in energy band gap by doping PVA with wt\% $\mathrm{NaNO}_{3}$ is observed. Finally, it is observed that by rising the dopant content $\mathrm{NaNO}_{3}$ to polymer PVA then optical conductivity, optical edge of absorption, a direct band of energy, indirect band gaps decrease as well as the refractive index increased up to certain concentration levels.

\section{ACKNOWLEDGMENT}

We would say thanks to (Department of Science and Technology) DST, India Government, Delhi, for the reward of Level-1, DST - FIST, Physics Department, Koneru.Lakshmaiah Educational.Foundation and great thanks to KLEF for providing infrastructure facilities (Perform supercomputers) and provision to conduct an investigation.

\section{REFERENCES}

1. Y. Cui, L. Xinmiao, C. Jingchao, C. Zili, W. Qinglei, H. Weisheng, L. Xiaochen, L. Zhihong, C. Guanglei, F. Jiwen, Applied Material Interfaces, 9, 8737(2017), DOI:10.1021/acsami.6b16218

2. S.B. Aziz, O.G. Abdullah, A.M. Hussein, H.M. Ahmed, Polymers, 9, 626(2017), DOI: 10.3390/polym9110626

3. K. Rama Mohan, V.B.S. Achari, V.V.R.N. Rao, A.K. Sharma, Polymer Test, 30, 881(2011), DOI: 10.1016/j.polymertesting.2011.08.010

4. S.B. Aziz, R.T. Abdulwahid, H.A. Rsaul, H.M. Ahmed, In situ, Journal of Material Science, 27, 4163(2016), DOI: 10.1007/s10854-016-4278-y

5. I. Roppolo, M. Sangermano, and A. Chiolerio, Functional and Physical Properties of Polymer Nanocomposites, 7, 139(2016), DOI:10.1002/9781118542316.ch7

6. S.B. Aziz, S. Hussein, A.M. Hussein, S.R. Saeed, International Journal of Metals 2013, Article ID, 123657, (2013), DOI:10.1155/2013/123657

7. N Krishna Jyothi, K Vijaya Kumar, G Sunita Sundari, P Narayana Murthy, Indian Journal of Physics, 90(3), 289 (2016), DOI:10.1007/s12648-015-0758-9

8. N. Krishna Jyothi, K. K. Venkata Ratnam, P. Narayana Murthy, K. Vijaya Kumar, Materials Today: Proceedings, 3, 21(2016), DOI:10.1016/j.matpr.2016.01.112 
RASĀYAN J. Chem.

Vol. 14 | No. 2 |760-767| April - June | 2021

9. N Krishna Jyothi, K. K Venkataratnam, P Narayana Murty, K Vijaya Kumar, Bulletin of Material Science, 39(4), 1047 (2016), DOI:10.1007/s12034-016-1241-8

10. N. Senthilvelan, G. Rajarajan, S. Sivakumar, J. Elanchezhiyan, A. Jegatheesan. Rasayan Journal Chemistry, 10, 245(2017), DOI:10.7324/RJC.2017.1011566

11. Y. Anantha Lakshmi, K. Swapna, K. Siva Rama Krishna Reddy., M. Venkateswarlu. S. Mahamuda, \& A.S. Rao, Journal of Luminescence, 211, 39(2019), DOI:10.1016/j.jlumin.2019.03.022

12. C. B. Annapurna Devi, S. Mahamuda, M. Venkateswarlu, K. Swapna, A. Srinivasa Rao, G. Vijaya Prakash, Optical Materials, 62, 569(2016), DOI:10.1016/j.optmat.2016.11.016

13. N. Deopa, A.S. Rao, S. Mahamuda, M. Gupta, M. Jayasimhadri, D. Haranath, G. V. Prakash, Journal of Alloys and Compounds, 708, 911(2017), DOI:10.1016/j.jallcom.2017.03.020

14. C. B. A. Devi, K. Swapna, S. Mahamuda, M. Venkateswarlu, M. V. V. K. S. Prasad, K. Siva Rama Krishna Reddy, A. S. Rao, Optics and Laser Technology, 111, 176(2018), DOI: 10.1016/j.optlastec.2018.09.051

15. P. Rekha Rani, M. Venkateswarlu, S. Mahamuda, K. Swapna, N. Deopa, A. S. Rao, Journal of Alloys and Compounds, 787, 503(2019), DOI:10.1016/j.jallcom.2019.02.088

16. K. Siva Rama Krishna Reddy, k. Swapna, S. Mahamuda, M. Venkateswarlu, M. V. V. K. Srinivas Prasad, A. S. Rao, G. V. Prakash, Optical Materials, 79, 21(2018), DOI: 10.1016/j.optmat.2018.03.005

17. M. Venkateswarlu, S. Mahamuda, K. Swapna, A. Srinivasa Rao, A. M. Babu, S. Shakya, G. V. Prakash, Journal of Luminescence, 175, 225(2018), DOI:10.1016/j.jlumin.2016.03.006

18. T. Yamaki, T. Yamada, K. Asai, K. Ishigure and H. Shibata, Thin Solid Films, 22, 327(1998), DOI: 10.1016/S0040-6090(98)00717-2

19. T. Kamakshi, G. Sunita Sundari, Harikrishna Erothu, R. Subhakaran Singh, Rasayan Journal Chemistry, 12(2), 531(2019), DOI:10.31788/RJC.2019.1225054

20. M. Pattabi, B. Saraswathi Amma, K. Manzoor, Material Research Bulletin, 42, 828(2007), DOI: 10.1016/j.materresbull.2006.08.029

21. H. Dianhar, A. W. Winata, S. Handayani, P. Sugita, D. U. C. Rahayu, Rasayan Journal of Chemistry, 13(3),1801(2020), DOI:10.31788/ RJC.2020.1335808

22. WE. Mahmoud, HM. El-Mallah, Journal of Physics D: Applied Physics, 42(3), 35502(2008), DOI: $10.1063 / 1.4930586$

23. V. Chitra, D. Roopsingh, Rasayan Journal of Chemistry, 12(4),2124(2019), DOI: $10.31788 /$ RJC.2019.1245431

24. N. Senthilvelan, G. Rajarajan, S. Sivakumar, J. Elanchezhiyan, A. Jegatheesan, Rasayan Journal Chemistry, 10, 245(2017), DOI:10.7324/RJC.2017.1011566

[RJC-5964/2020] 